\section{Effects of managers' environmental attitudes on waste management practices in small hotels in Accra}

Effects of managers' environmental attitudes

\author{
Ishmael Mensah \\ Hospitality and Tourism Management, University of Cape Coast, \\ Cape Coast, Ghana, and \\ Emmanuel Twumasi Ampofo \\ Human Resources and Organisational Development, \\ Kwame Nkrumah University of Science and Technology, Kumasi, Ghana
}

Received 11 August 2020 Revised 18 September 2020 13 October 2020 Accepted 17 November 2020

\begin{abstract}
Purpose - Drawing on the upper echelons theory, the study examines the effects of environmental attitudes of hotel managers on the waste management practices of small hotels in the context of a developing country.

Design/methodology/approach - A survey involving 246 managers of small hotels in the Accra Metropolitan Area was undertaken using a questionnaire that was based on the Waste Management Hierarchy and the revised New Ecological Paradigm (NEP) scales.

Findings - Results of the study showed that environmental attitudes of managers significantly influence the waste management practices of hotels, specifically, the anti-anthropocentricism, anti-exceptionalism, eco-crisis and balance-of-nature dimensions of the NEP scale. The study also found that all the environmental attitude dimensions had more significant effects on the waste disposal option because usually in developing countries, small hotels by their nature are more predisposed to undertaking this option.

Research limitations/implications - Future studies should use longitudinal data to make causal inferences and consider the use of a rigorous statistical test such as common latent factor analysis.

Practical implications - Waste management problems in small hotels require softer sustainability strategies geared towards creating environmental awareness and inculcating the right environmental values in hotel managers in order to change the way managers view the environment.

Originality/value - Results of the study indicate that in the context of small hotels in developing countries, managers with eco-centric attitudes are more likely to engage in less expensive waste management practices rather than the most environmentally-friendly options.
\end{abstract}

Keywords Waste management, Environmental attitude, Upper echelons theory, Small hotels

Paper type Research paper

\section{Introduction}

Environmental attitude is crucial for the attainment of environmentally sustainable practices because most of the environmental problems confronting the globe are attitudinal. Schultz et al. (2004, p. 31) define environmental attitude as "the collection of beliefs, affect, and behavioural intentions a person holds regarding environmentally related activities or issues". Fishbein and Ajzen (1975) have also indicated that attitude is an effective predictor of behavioural and intentions. Molina-Azorin et al. (2009) have also underscored the importance of examining hotel managers' attitudes towards environmental management by emphasising

(C) Ishmael Mensah and Emmanuel Twumasi Ampofo. Published in International Hospitality Review. Published by Emerald Publishing Limited. This article is published under the Creative Commons Attribution (CCBY 4.0) licence. Anyone may reproduce, distribute, translate and create derivative works of this article (for both commercial and non-commercial purposes), subject to full attribution to the original publication and authors. The full terms of this licence may be seen at http://creativecommons. org/licences/by/4.0/legalcode 
IHR

35,1

110

that the attitudes of managers are directly linked to the performance of their hotels. According to Aragón-Correa et al. (2004), organisational commitment to environmental management has been attributed largely to the efforts of top management. In small to medium enterprises, the attitude of managers is critical to the success of those organisations (Dalotă and Grigore, 2010). There is also empirical evidence which points to the fact that green practices among small hotels are mainly driven by owner-managers' ethical concerns about the natural environment (Tzschentke et al., 2008). One area of pro-environmental behaviour is waste management, which reflects the collection, transportation, storage, treatment, recovery and disposal of waste (Bilitewski et al., 1994). According to Mensah (2019), hotels by their nature generate lots of waste and this adds to the waste management problems in most destinations. Typically, a hotel guest can produce $1 \mathrm{~kg}$ of waste a day and that accumulates to thousands of tonnes of waste annually (IHEI, 2002; Zorpas et al., 2012).

Studies on the link between environmental attitude and pro-environmental behaviour have not been conclusive. While a study by Park et al. (2014) has shown the effect of environmental attitude on pro-environmental behaviour, other studies have shown that the environmental management activities of firms do not necessarily follow the positive values or attitudes of owners and managers (Cassels and Lewis, 2011). Also, managers of small hotel firms have been found to take very little action to reduce the environmental impacts of their hotels (Webster, 2000). This has been attributed to several factors, including low levels of environmental awareness and "eco-literacy" among owner-managers (Chan, 2011; Tilley, 2000; Vernon et al., 2003) and lack of resources (Hoogendoorn et al., 2015). The New Ecological Paradigm (NEP) scale is the most widely used measure of environmental attitudes (Hawcroft and Milfont, 2010). However, such studies have focused on the application of the NEP model without linking it to pro-environmental behaviour. Also, those studies did not treat the five dimensions of the scale namely balance-of-nature, ecocrisis, anti-exceptionalism, limits-to-growth and anti-anthropocentrism differently. Moreover, previous studies have linked environmental attitudes to pro-environmental behaviour in general and not waste management specifically. However, in small hotels, one important area of pro-environmental behaviour is waste management. This is because waste generation is one of the most significant impacts of tourism in general and hotels in particular (Bohdanowicz, 2005; Mateu-Sbert et al., 2013). Hotels usually offer a range of services to clients and during the process of service delivery, resources such as food, water, paper, plastics, bottles and clothes are used. This is usually a significant addition to the waste stream of destinations. However, most of the studies on waste management practices have been undertaken in larger hotels (Ball and Taleb, 2011; Bohdanowicz, 2005; Phu Pham et al., 2018; Pirani and Arafat, 2014; Zorpas et al., 2015). The role of the manager in ensuring that wastes are appropriately managed in a small hotel cannot be discounted. This is because, in such hotels, the manager is usually the ultimate decision-maker for managing solid waste (Radwan et al., 2012). In spite of this, there is a dearth of empirical evidence about how the environmental attitudes of managers of small hotels influence the waste management practices of hotels.

Given the vital decision-making role of managers of small hotels (Radwan et al., 2012), their environmental attitude is likely to shape their waste management practices. Using the upper echelon theory as a theoretical framework, this study examines how the different dimensions of environmental attitudes of hotel managers influence the different levels of waste management practices of small hotels using the Waste Management Hierarchy model. The current study makes at least two important contributions to research. First, this is the first empirical research to link the NEP scale to pro-environmental behaviour, specifically waste management in small hotels in a developing country context. Also, this study extends knowledge on the effects of environmental attitude on pro-environmental behaviour by examining the effects of different dimensions of environmental attitude on the 
adoption of different waste management options by managers of small hotels in developing countries.

\section{Theory and hypothesis development \\ 2.1 Upper echelons theory}

The upper echelons theory can provide a useful understanding of how managers' environmental attitudes influence their waste management practices. The theory suggests that the outcome of an organisation is heavily influenced by the individual manager's choices, which in turn are affected by his/her characteristics (Hiebl, 2014). According to Liao (2018), upper echelons theory indicates how the values, experiences and cognition of corporate executives greatly affect their perceptions and interpretations of the environment and thus affect their decision-making. This theory is founded on the logic that "first, executives act based on their personalised interpretations of the strategic situations they face, and secondly, these personalised construals are a function of the executives' experiences, values, and personalities" (Hambrick, 2007, p. 334). CEOs influence how environmental issues are perceived and addressed (Cho et al., 2019). According to Zutshi and Sohal (2004), kind of leadership and support for sustainability provided by top management is vital because it can influence an organisation's understanding and awareness of environmental issues. Research on environmental management has proven that top management influences the response of organisations to environmental issues (e.g. Autry et al., 2013). The direct involvement of top management in responsible environmental management results in the commitment of organisations to environmental management (Aragón-Correa et al., 2004). Managers' awareness of environmental problems, as well as their concerns about the environment, has been identified as a predictor of environmental management in hotels (e.g. Park and Kim, 2014; Park et al., 2014).

\subsection{Environmental attitude and waste management practices}

Kollmuss and Agyeman (2002, p. 242) define attitude as "the enduring positive or negative feeling about some person, objective, or issues". Environmental attitude, on the other hand, is the beliefs, feelings and behavioural intentions that people hold about environmentallyrelated activities or issues (Schultz, et al., 2004). Generally, people's behaviours are often triggered by their perceptions of reality (Ferris et al., 1996). Thus, based on the socialpsychological theory, attitude is an effective predictor of behaviour and intentions (Fishbein and Ajzen, 1975). Generally, it has been empirically evidenced that individuals' ecological worldview is a strong predictor of environmental behaviour (Brügger, Kaiser and Roczen, 2011). Other studies have found that managers' and owners' psychological factors such as values and environmental attitudes underlie the adoption of environmental management practices by their organisations (e.g. Jabbour et al., 2013; Park et al., 2014; Williams and Schaefer, 2013). In a study that sought to apply Ajzen's theory of planned behaviour, Cordano and Frieze (2000) identified managers' attitudes as an important antecedent to preferences for source reduction activity. Dibrell, Craig, and Hansen (2011) proved that firms with managers who hold strong beliefs about the environment tend to implement a set of practices geared towards better management of environmental issues. However, most of these studies were undertaken in bigger organisations in developed countries. Managers of such organisations may profit from the advantages of technology, education, finance and management (Zhang and London, 2011). For instance, Tsai et al. (2014) have found out that managers who work for upscale hotels have higher green hotel attitudes than managers of typical hotels.

Within the hotel industry, particularly hotels, the adoption of green practices is dependent on the owner's or manager's environmental beliefs (Scholz and Voracek, 2016). Some studies

\section{Effects of managers' environmental attitudes}


IHR

35,1

have found the effect of environmental attitude of managers on environmental management practices to be significant. For example, in a study on the environmental attitudes of managers of small European hotels, Tzschentke et al. (2008) indicated that many hotel managers undertook environmental initiatives in their hotels based on their environmental ethics. In an online survey of 206 top managers in some hotels in the United States, Park et al. (2014) found that environmental attitudes of managers influence the environmental management activities of hotels through perceived benefits of the environmental programmes. In a related study, Bohdanowicz (2005) discovered that chain hotel managers had more positive attitudes towards environmental issues than their counterparts in independent hotels. Also, Park and Kim (2014) demonstrated that top managers' attitudes towards environmental issues had less impact on environmental initiatives in chain hotel companies compared to independent hotel companies.

However, studies on the effect of environmental attitude on environmental performance have not been conclusive. Mensah (2020) asserts that though managers of small hotels in Accra embarked on waste management practices geared towards waste reduction and prevention, which could be borne out of economic imperatives rather than environmental concerns. Some other studies have also shown that environmental attitudes have varied, but normally very small, effect on the pro-environment behaviour (Anguera et al., 2000; Kasim, 2009; Pryce, 2001). In the context of small hotels, other situational factors could interfere with the environmental attitudes of managers, in that managers with pro-environmental factors may be constrained in taking steps to manage the environment. To illustrate, a study by Kasim (2009) in Kuala Lumpur demonstrated that although managers of small- and mediumsize hotels had positive attitudes towards environmental issues, their attitudes did not predict actual environmental management practices. Kim and Yoon's (2010) study on Korean hotels shows that though general managers were well aware of waste management and recycling, most of them thought that eco-friendly practices are costly. However, in the previous studies, the environmental attitude was treated as a unidimensional variable though there are different dimensions of environmental attitude in the literature and the predictive power of the dimensions on pro-environmental behaviour could vary.

Thompson and Barton (1994) distinguish between two motives for pro-environmental behaviour namely, ecocentrism which is appreciating nature for its own sake, and anthropocentrism which is appreciating nature because of its benefits to humans. They found out that ecocentrism had a positive relationship with pro-environmental behaviours while there was a negative relationship between anthropocentrism and pro-environmental behaviour. Also, Nordlund and Garvill (2002) in a study based on Schwartz's (1977) normactivation theory found out that individuals engaging in pro-environmental behaviour demonstrated an eco-centric value orientation and a stronger moral obligation to protect the environment. Thus, those with ecocentric motives were more predisposed to proenvironmental behaviour. According to Holden (2008), anthropocentrism was traditionally the dominant approach in Western decision-making prior to the development of modern environmentalism.

The NEP Scale is composed of two main directions: ecocentric and anthropocentric views (López-Bonilla and López-Bonilla, 2016). Amérigo et al. (2007) also identified a three-factorial structure of environmental beliefs namely anthropocentric, biospheric and ego-bio-centric. Schultz (2001) on the other hand identified three different categories of environmental attitudes, namely importance of self over the environment (egoistic), importance of the environment for people (socio-altruistic) and importance of the environment for itself (ecocentric). In a study of owner-managers' contribution to sustainable solid waste management in homestay accommodation facilities in Cape Coast, Ghana, Agyeiwaah (2020) identified four different attitudes namely eco-crises, tendency to blame others, no limit to the growth and anti-anthropocentrism. The study concluded that owner-managers contribute to sustainable 
solid waste management based on the values behind their actions and the extent to which they were aware of the negative consequences of their actions on the environment. According to Dief and Font (2012), though empirical research has indicated that eco-oriented managers may play a role in corporate greening, there is a need for more empirical analyses in this area. Based on the above, it is hypothesised that:

H1a. Small hotel managers' environmental attitudes (as a composite variable) will be positively related to waste management practices of (a) prevention, (b) reduction, (c) reuse, (d) recycle, (e) recovery and (f) disposal, after controlling for the effects of demographic variables.

H1b. Small hotel managers' environmental attitudes (i.e. balance of nature, eco-crisis, limits-to-growth, anti-exceptionalism and anti-anthropocentricism) will be positively related to waste management practices of (a) prevention, (b) reduction, (c) reuse, (d) recycle, (e) recovery and (f) disposal, after controlling for the effects of demographic variables.

\section{Methodology}

\subsection{Study context and design}

There is no consensus as to what constitutes a small hotel. The exact meaning of the term differs from country to country and usually depends on the designation in each country or the opinions of researchers. On account of this, small hotels have been classified based on different criteria such as the number of guestrooms, number of employees or quality rating. Following Milohnic (2006), in the current study, a small hotel is defined as a hotel with rooms not exceeding 50 and with not more than 2-star rating, based on Ghana Tourism Authority (GTA) classification. Accra was chosen for this study because of the prevailing waste management challenges coupled with the proliferation of small hotels in the city, which tends to worsen the sanitation problem. It has been reported that Accra generates an estimated 3,000 metric tons of waste per day, of which about $30 \%$ of which remain uncollected (Today Newspaper, 2018). The contribution of hotels to this waste management problem cannot be underestimated in the fight of the government to turn Accra into the cleanest city in Africa by 2020. Also, the number of small hotels springing up in the city is on the ascendancy. In 2015, there were 703 small hotels in the Greater Accra Region (GTA, 2016). About 97\% of the total number of hotels in the region could be classified as small hotels. Although the amount of waste generated by individual small hotel units is usually small compared to that of larger hotels, the cumulative impact of the wastes generated by the increasing number of small hotels on the environment could be catastrophic (Mensah, 2006). Small hotels usually do not have the resources and management capacity to embark on appropriate waste management practices.

\subsection{Participants and procedures}

The population of the study comprised of all managers of all small hotels in the Accra Metropolitan Area. According to GTA, there were 703 small hotels in the Greater Accra Region in 2015. Out of this, 684 were located in the Accra Metropolitan Assembly (AMA). The sample size was therefore based on the population of 684 , a margin of error of $5 \%$, a confidence interval of $95 \%$ and a sample proportion of $50 \%$. This culminated in a sample size of 249 , which was determined using the Raosoft sample size calculator. Though the actual sample size was 249,16 was added to cater for possible non-responses and this resulted in a sample of 265. The simple random sampling method was used to select respondents. Using the lottery method, all the small hotels on the list were numbered and random numbers

\section{Effects of managers' environmental attitudes}


IHR

35,1

generated were used to select the hotels from the list until all the 265 hotels were selected. Once a hotel was selected, the General Manager was personally contacted by a trained Field Assistant for the survey.

This paper is part of a larger study on waste management practices in small hotels in Accra. Data were collected from a cross-section of hotel managers through the survey method. Before data collection for the study, a pre-test was undertaken in 15 hotels in Cape Coast, and Elmina, which are two popular tourist destinations in the Central Region of Ghana. Based on feedback on the pre-test from Field Assistants, the major issues that emerged from the pre-test were non-exhaustive response sets and respondents' lack of understanding of some of the questions because they were not properly worded or structured. Some questions were subsequently revised to ensure greater respondent comprehension. Also, the questionnaire was restructured to reduce respondent's burden of interest. The actual data collection was undertaken between June and September 2018 by a team of six Field Assistants who had been trained on data collection. Field Assistants made personal and repeated visits to the hotels which had been randomly selected to self-administer the questionnaires to managers. Hotel managers who failed to complete the questionnaire were substituted with managers of other small hotels by drawing additional samples from the sampling frame. Out of the 265 self-administered structured questionnaires, 260 were collected representing a response rate of $98 \%$. The five questionnaires were found to be unsuitable for the analysis due to non-responses to some of the important questions and were discarded. Initially, low reliability scores were recorded for 259 responses. To remedy this situation, 14 responses which had inadequate variation were removed from the analysis. After the deletion, satisfactory reliabilities were recorded for the variables under study. Thus, 246 responses were used for the analysis in this study.

\subsection{Measures}

3.3.1 Waste management practices. Waste management practices were assessed using a 33item scale based on the WMH which provides a model of the potential options for managing waste (Waste Online, 2006). The scale assesses six hierarchical waste management practices, namely: prevention (6), reduction (8), reuse (7), recycle (6), recovery (3) and disposal (3). Sample items include: "Purchasing from local sources" (prevention), "Using energy-efficient equipment and products" (reduction), "Repairing broken equipment instead of purchasing a one new" (reuse), "Recycling wastewater for other uses" (recycle), "Composting organic waste" (recovery) and "Providing dustbins for collection and dumping of waste" (disposal). Response options ranged from 1 (never) to 6 (very frequently). This study recorded Cronbach $\alpha$ values of $0.778,0.843,0.836,0.871,0.885$ and 0.754 for prevention, reduction, reuse, recycle, recovery and disposal respectively.

3.3.2 Environmental attitudes. The revised NEP scale developed by Dunlap et al. (2000) was utilised to measure environmental attitudes. The scale has 15 items and comprises five dimensions, that is, balance of nature, eco-crisis, limits-to-growth, anti-exceptionalism and anti-anthropocentrism. Each dimension is measured with three items. Sample items are: "When humans interfere with nature it often produces disastrous consequences" (balance in nature); "Humans are severely abusing the environment" (eco-crisis); "Human ingenuity will ensure that we do not make the Earth uninhabitable" (anti-exceptionalism); "The Earth has plenty of natural resources if we just learn how to develop them" (limits-to-growth); and "Humans have the right to modify the natural environment to suit their needs" (antianthropocentrism). A five-point Likert scale ranging from $1=$ strongly disagree to $5=$ strongly agree was used in this study. Cronbach's $\alpha$ values of $0.767,0.781,0.744$ and 0.774 were reported for balance in nature, eco-crisis, anti-exceptionalism and antianthropocentrism respectively. Cronbach's $\alpha$ was not reported on limits-to-growth, since 
all its three items recorded poor standardised factor loadings in the confirmatory factor analysis (CFA).

3.3.3 Controlvariables. Demographic variables, which include age, gender, income, marital status and education, were treated as control variables in this study. Research indicates that these variables have confounding influence on pro-environmental behaviour, including waste management practices (e.g. Stern, 2000).

\section{Effects of managers' environmental attitudes}

\subsection{Data analysis}

Data were analysed with SPSS version 25 and AMOS version 25. Prior to testing the study's hypotheses, the following preliminary analyses were performed. Data were cleaned by using the Expected Maximisation technique to replace data that were missing completely at random. Seven environmental attitudes items ("The balance of nature is strong enough to cope with the impacts of modern industrial nations", "The so-called 'ecological crisis' facing humankind has been greatly exaggerated", "Human ingenuity will ensure that we do not make the Earth uninhabitable", "Humans will eventually learn enough about how nature works to be able to control it" "The Earth has plenty of natural resources if we just learn how to develop them" and "Humans have the right to modify the natural environment to suit their needs") were reversed scored. All variables were normally distributed since skewness and Kurtosis were between -2 and +2 (refer to Table 2, Tabachnick and Fidell, 2007). Additionally, descriptive statistics including frequency and percentages were used to analyse the demographic profile of participants. Also, mean and standard deviations were determined for all variables. Also reliability test was performed in SPSS to determine the internal consistency of variables. A bivariate correlational analysis was performed to determine the inter-relationships among the variables under study.

CFA in AMOS was used to assess the goodness-of-fit of the hypothesised model and to test the validity and reliabilities of the variables under study. In the present study, a good fitted model was assessed using the following statistics: CMIN $\left(\chi^{2} / \mathrm{df}\right)<0.05$, Chi square $\left(\chi^{2}\right) \mathrm{p}$ value $>0.05$, comparative fit index $(\mathrm{CFI}) \geq 0.90$, RMR $>0.07$, Tucker-Lewis index $(\mathrm{TLI})>0.95$ and root mean square error of approximation (RMSEA) $<0.05$ (Hu and Bentler, 1999). Because the sample size was relatively small given the number of variables in the study, item parcel was created for four waste management practices, which include prevention, reduction, reuse and recycle. Items of waste management practices of recovery and disposal were not parcelled, since they had only three items each. Moreover, items of environmental attitudes were not parcelled in this study, because each attitude had three dimensions. A two-step hierarchical multiple regression analysis was employed to test the current study's hypotheses. First, the four demographic characteristics were entered into step 1 and their effects on the dependent variables were determined. Thereafter, the independent variables were included in model in step 2 to determine how much they will influence the dependent variables when the effects of demographic variables are considered.

In the present study, Harman's single factor test was employed to test the potential effects of common method bias [CMB] (Podsakoff et al., 2003). Here, factor analysis in SPSS was performed using all independent variables. The number of factors was constrained to 1 . The first component explained about $27 \%$ variance of all the independent variables in the model, which is less than the threshold of $50 \%$. Thus, in this study, CMB was not a concern.

\section{Results}

Table 1 indicates results relating to the demographic characteristics of the study's participants. Out of 246 participants, $140(56.9 \%)$ were males, $135(54.9 \%)$ were married and $140(56.9 \%)$ were less than 40 years. Ninety-nine $(40.2 \%)$ of the participants were diploma or 
IHR

35,1

\begin{tabular}{|c|c|c|}
\hline & Frequency & Percent \\
\hline \multicolumn{3}{|l|}{ Age } \\
\hline Less than 20 years & 10 & 4.1 \\
\hline $21-29$ years & 49 & 19.9 \\
\hline 30-39 years & 81 & 32.9 \\
\hline $40-49$ years & 66 & 26.8 \\
\hline $50-59$ years & 30 & 12.2 \\
\hline 60 or more & 10 & 4.1 \\
\hline \multicolumn{3}{|l|}{ Gender } \\
\hline Male & 140 & 56.9 \\
\hline Female & 106 & 43.1 \\
\hline \multicolumn{3}{|l|}{ Highest education level } \\
\hline Primary school & 4 & 1.6 \\
\hline Secondary/Technical & 33 & 13.4 \\
\hline Training college & 66 & 26.8 \\
\hline Polytechnic/University graduate & 99 & 40.2 \\
\hline Postgraduate & 44 & 17.9 \\
\hline \multicolumn{3}{|l|}{ Marital status } \\
\hline Single & 75 & 30.5 \\
\hline Married & 135 & 54.9 \\
\hline Separated & 26 & 10.6 \\
\hline widowed & 10 & 4.1 \\
\hline \multicolumn{3}{|l|}{ Income } \\
\hline Less than GHф50 & 7 & 2.8 \\
\hline GH $\not 50-$ GH $\not 250$ & 24 & 9.8 \\
\hline $\mathrm{GH} \propto 251-\mathrm{GH} \phi 450$ & 69 & 28.0 \\
\hline GHф451 - GHф650 & 99 & 40.2 \\
\hline GH\&651 and above & 47 & 19.1 \\
\hline \multicolumn{3}{|l|}{ Note(s): $N=246$} \\
\hline
\end{tabular}

first-degree holders and $33(13.4 \%)$ participants had completed secondary or technical schools. Most of the participants $(99,40.2 \%$ ) had their income between GHф451 and GHф650 and followed by $69(28.0 \%)$ participants who had their income between GHф251 and GH 450 .

Table 2 presents the results for mean, standard deviations, normality, reliability and CFA. In an initial CFA, the results showed poor fit statistics, and low standardised factor loadings for the three items of limits-to-growth ("The Earth has plenty of natural resources if we just learn how to develop them", "We are approaching the limit of the number of people the Earth can support", and "The Earth is like a spaceship with very limited room and resources") and one item for waste management practice of disposal ("Open dumping of waste"). These four items were deleted, and CFA was performed again. The results demonstrated that all the remaining items had standardised factor loading above 0.50. Also, adequate construct reliability was obtained, because Cronbach's $\alpha$ values and composite reliabilities are greater than 0.70 (Hair et al., 2010). Adequate discriminant validity was obtained because average variance extracted (AVEs) exceed MSV, and AVEs are above ASV (Hair et al., 2010). Also, sufficient convergent validity was obtained, since AVEs are greater than 0.50, and AVEs are below composite reliabilities (Hair et al., 2010). Finally, the results showed good fit statistics $(\chi 2=81.383, \mathrm{df}=25, p=0.000), \mathrm{CFI}=0.957$, TLI $=0.941$, RMSEA $=0.049)$.

Table 3 shows results for inter-correlations among the variables under study. Environmental attitudes (as an aggregate variable) is significantly and positively correlated with prevention $(r=0.338, p<0.001)$, reduce $(r=0.467, p<0.001)$, reuse 


\begin{tabular}{|c|c|c|c|c|c|c|c|c|c|}
\hline Scale items & Mean & SD & Sk & $K$ & SFL & $\mathrm{CR}$ & AVE & MSV & $\begin{array}{l}\text { SQRT of } \\
\text { AVE }\end{array}$ \\
\hline $\begin{array}{l}\text { Prevention } \\
\text { Indicator } 1\end{array}$ & 4.587 & 0.731 & -0.489 & 0.504 & 0.578 & 0.725 & 0.580 & 0.486 & 0.762 \\
\hline Indicator 2 & & & & & 0.909 & & & & \\
\hline $\begin{array}{l}\text { Reduction } \\
\text { Indicator } 1\end{array}$ & 4.438 & 0.847 & -0.744 & 0.876 & 0.775 & 0.766 & 0.620 & 0.645 & 0.821 \\
\hline $\begin{array}{l}\text { Indicator } 2 \\
\text { Reuse }\end{array}$ & 3.738 & 3.643 & 1.076 & -0.433 & 0.800 & 0.753 & 0.584 & 0.464 & 0.766 \\
\hline $\begin{array}{l}\text { Indicator } 1 \\
\text { Indicator } 2\end{array}$ & & & & & $\begin{array}{l}0.697 \\
0.695\end{array}$ & & & & \\
\hline $\begin{array}{l}\text { Recycle } \\
\text { Indicator } 1\end{array}$ & $3.655 \mathrm{~s}$ & 3.655 & 1.083 & 0.225 & 0.804 & 0.818 & 0.692 & 0.652 & 0.832 \\
\hline Indicator 2 & & & & & 0.859 & & & & \\
\hline Recovery & 3.256 & 3.256 & 1.362 & -1.015 & & 0.891 & 0.733 & 0.654 & 0.856 \\
\hline $\begin{array}{l}\text { RV1 } \\
\text { RV2 }\end{array}$ & & & & & $\begin{array}{l}0.767 \\
0.890\end{array}$ & & & & \\
\hline $\begin{array}{l}\text { KVZ } \\
\text { RV3 }\end{array}$ & & & & & $\begin{array}{l}0.090 \\
0.904\end{array}$ & & & & \\
\hline $\begin{array}{l}\text { Disposable } \\
\text { DP1 }\end{array}$ & 4.564 & 1.226 & -0.764 & -0.050 & 0.763 & 0.762 & 0.615 & 0.428 & 0.784 \\
\hline DP3 & & & & & 0.805 & & & & \\
\hline $\begin{array}{l}\text { Environmental } \\
\text { attitudes }\end{array}$ & 3.406 & 0.733 & -0.285 & -0.220 & & 0.848 & 0.588 & 0.428 & 0.767 \\
\hline Balance of nature & & & & & 0.678 & & & & \\
\hline Eco-crisis & & & & & 0.663 & & & & \\
\hline Anti-exceptionalism & & & & & 0.663 & & & & \\
\hline Ant-anthropocentrism & & & & & 0.727 & & & & \\
\hline
\end{tabular}

Note(s): $\mathrm{Sk}=$ skewness; $K=$ Kurtosis; $\alpha=$ reliability; $\mathrm{CR}=$ composite reliability; $\mathrm{SFL}=$ standardised factor loading; AVE = average variance extracted; MSV = maximum shared variance; ASV = average shared variance

$(r=0.292, p<0.001)$, recycle $(r=0.269, p<0.001)$, recovery $(r=0.272, p<0.001)$ and disposal $(r=0.486, p<0.001)$. In terms of the individual environmental attitudes, the results demonstrate that anti-anthropocentrism is significantly and positively correlated with prevention $(r=0.214, p<0.01)$, reduce $(r=0.378, p<0.001)$, reuse $(r=0.170, p<0.01)$, recycle $(r=0.133, p<0.05)$, recovery $(r=0.128, p<0.05)$ and disposal $(r=0.384, p<0.001)$. Additionally, anti-exceptionalism is significantly and positively associated with prevention $(r=0.377, p<0.001)$, reduce $(r=0.467, p<0.001)$, reuse $(r=0.286, p<0.001)$, recycle $(r=0.293, p<0.001)$, recovery $(r=0.283, p<0.001)$ and disposal $(r=0.468, p<0.001)$. Also, eco-crisis is significantly and positively associated with prevention $(r=0.185, p<0.01)$, reduce $(r=0.259, p<0.001)$, reuse $(r=0.129, p<0.05)$, recycle $(r=0.140, p<0.05)$, recovery $(r=0.202, p<0.01)$ and disposal $(r=0.279, p<0.001)$. Moreover, balance in nature is significantly and positively associated with prevention $(r=0.276, p<0.001)$, reduce $(r=0.299, p<0.001)$, reuse $(r=0.208, p<0.01)$, recycle $(r=0.269, p<0.001)$, recovery $(r=0.225, p<0.001)$ and disposal $(r=0.263, p<0.001)$.

Table 4 presents results for effects of environmental attitudes on waste management practices, after controlling for the effects of five demographic variables. With regard to environmental attitudes as a composite variable, the result demonstrates its significant and positive relationship with all the waste management dimensions, namely prevention $(\beta=0.344, t=5.635)$, reduce $(\beta=0.482, t=8.664)$, reuse $(\beta=0.286, t=4.645)$, recycle $(\beta=0.288, t=4.675)$, recovery $(\beta=0.279, t=4.645)$ and disposal $(\beta=0.544, t=10.138)$, thereby confirming H1a. 
IHR

35,1

118

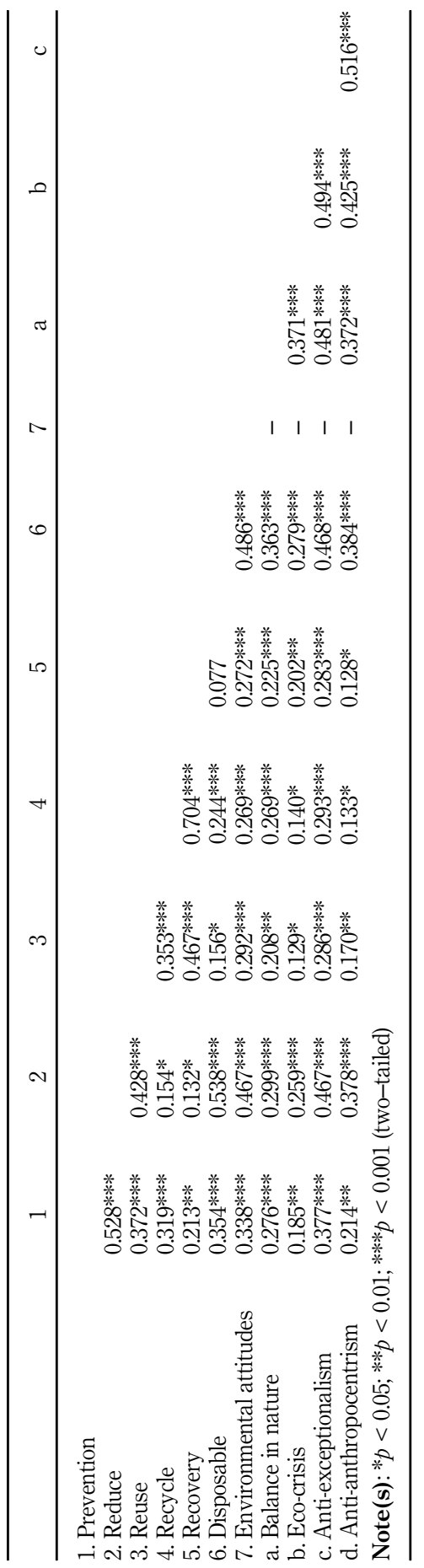

Table 3.

Correlations 


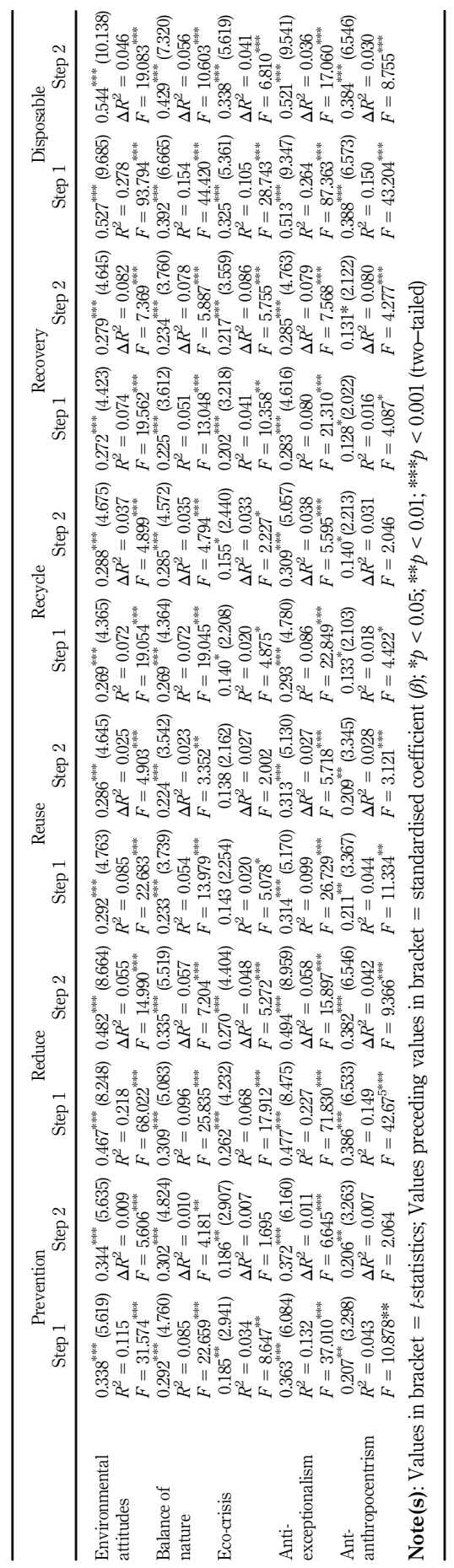

\section{Effects of managers' environmental attitudes

Table 4. Results for effects of environmental attitudes on waste management practices 
IHR

35,1

Specifically, balance of nature had significant and positive effect on prevention $(\beta=0.302$, $t=4.824)$, reduce $(\beta=0.335, t=5.519)$, reuse $(\beta=0.224, t=3.542)$, recycle $(\beta=0.285$, $t=4.572)$, recovery $(\beta=0.234, t=3.760)$ and disposal $(\beta=0.429, t=7.320)$. Furthermore, eco-crisis was significantly and positively related to prevention $(\beta=0.186, t=2.907)$, reduce $(\beta=0.270, t=4.404)$, recycle $(\beta=0.155, t=2.440)$, recovery $(\beta=0.217, t=3.559)$ and $\operatorname{disposal}(\beta=0.338, t=5.619)$. However, the relationship between eco-crisis and reuse was not significant $(\beta=0.138, t=2.162)$. Additionally, anti-exceptionalism had significant and positive relationship with prevention $(\beta=0.372, t=6.160)$, reduce $(\beta=0.494, t=8.959)$, reuse $(\beta=0.313, t=5.130)$, recycle $(\beta=0.309, t=5.057)$, recovery $(\beta=0.285, t=4.763)$ and disposal $(\beta=0.521, t=9.541)$. Finally, the results show that ant-anthropocentrism significantly and positively influenced prevention $(\beta=0.206, t=3.263)$, reduce $(\beta=0.382$, $t=6.546)$, reuse $(\beta=0.209, t=3.345)$, recycle $(\beta=0.140, t=2.213)$, recovery $(\beta=0.131$, $t=2.122)$ and disposal $(\beta=0.384, t=6.546)$. Thus, the results partially support H1b.

\section{Discussion, conclusion and implications}

The results indicate that based on the NEP, managers who believed that human activities impact the balance of nature (Balance of nature), humans are the cause of detrimental harm to the physical environment (eco-crisis), humans are not exempt from the constraints of nature (Anti-exemptionalism) and that humans have the right to modify and control the natural environment (Anti-anthropocentism) would institute measures to manage waste based on the $\mathrm{WMH}$, namely prevention, reduction, reuse, recycle, recover and disposal. The results indicated that environmental attitudes are positively related to waste management practices of prevention, reduction, reuse, recycle, recovery and disposal. This finding further supports the propositions of social psychological theory that attitude is an effective predictor of behaviour and intentions (Fishbein and Ajzen, 1975).

This means managers of small hotels who hold eco-centric views tend to initiate policies and programmes geared towards managing the waste generated by the hotels. This finding is explained by the upper echelons theory which points to the fact that organisations are reflections of their top executives. Thus, in smaller hotels, managers usually have the leeway to formulate and implement certain decisions through the lens of their personal experiences, values and personalities. Managers of small hotels who normally have all the executive powers to determine the course of their organisations can therefore determine the extent to which the hotels undertakes waste management practices geared towards safeguarding the environment. Therefore, a hotel manager with a pro-environmental attitude is more likely to institute measures that will result in the reduction of the amount of waste generated by his/ her hotel. Thus, the assertion by Zutshi and Sohal (2004) that top management leadership and support for sustainability can influence an organisation's understanding and awareness of environmental issues holds true for small hotels. It is the eco-centric views that significantly influence waste management practices in small hotels. The results of this study corroborate that of Thompson and Barton (1994) and Nordlund and Garvill (2002) that it is those with ecocentric views who are more predisposed to engaging in pro-environmental behaviour.

Additionally, the results demonstrate that all the environmental attitude dimensions had more significant effects on waste disposal practices compared to the remaining practices adopted in managing waste. This is against the fact that waste disposal is the least ideal waste management practice within the hierarchy of waste management practices as it exerts the greatest environmental impact. However, the finding is not surprising, since small hotels by their nature are more predisposed to undertaking waste disposal as a waste management option (Erdogan and Baris, 2007; Mensah, 2006; Radwan et al., 2012). Indeed, waste disposal is the default waste management practice for especially small hotels in developing countries. This could be attributed to the fact that such hotels usually do not have adequate resources to 
embark on environmental management (Kasim, 2009). As a result, managers are more concerned about the economic affordability and socio-cultural acceptability of waste management practices instead of environmental effectiveness (Agyeiwaah, 2020). Waste disposal presents the easiest waste management option for managers of small hotels as it does not require significant investments, unlike reuse, recycle and recovery options.

The results further showed that the predictive power of anti-exceptionalism on waste management practices was greater. This suggests that managers who hold a strong belief that humans are not exempted from the constraints of nature are more likely to undertake waste management practices in their hotels. This is followed by balance-of-nature and antianthropocentricism. Eco-crisis had the weakest predictive power on waste management practices, which could be explained that be attributed to the fact that such views have been described as socio-altruistic, that is, belief in the importance of the environment for people (Schultz, 2001). Thus, people who hold such views do not value the environment for its own sake but for the sake of humans. Moreover, the results showed that reduction and prevention are the second and third highest in terms of impacts of environmental attitudes on waste management practices. Waste reduction and prevention usually require attitudinal change on the part of management, staff and guests of the hotels without the need to make significant investments in any input.

In conclusion, the fact remains that the creation of waste is more of an attitudinal problem, and therefore addressing the problem requires changing people's beliefs and values regarding the environment. Attitudinal problems are best resolved with attitudinal changes. Therefore, the extent to which a small hotel undertakes waste management practices is significantly influenced by the environmental attitudes of the manager, particularly antiexceptionalism.

\subsection{Theoretical implications}

This study makes some contributions to research. First, it has contributed to the existing literature on the relationship between environmental attitudes and pro-environmental behaviour in the context of a developing country. Though the NEP scale has been widely used in previous research on environmental attitudes, such studies have focused on the application of the model without linking it to pro-environmental behaviour. Also, the study has provided evidence to the effect that different environmental attitude dimensions based on the NEP scale influence different waste management options undertaken by small hotels. However, in the context of small hotels in developing countries, managers with eco-centric attitudes are more likely to engage in less expensive waste management practices rather than the most environmentally-friendly options. Finally, the results of the study validate the upper echelons theory which suggests that the outcome of an organisation is significantly influenced by the personal factors of CEOs and top managers including their experiences, values and personalities. In this study, the environmental attitudes of managers significantly influenced the waste management practices of the hotels.

This study employed environmental attitudes as an independent variable. Future research that broadens the scope to include social-demographic, organisational and other contextual factors would help provide a nuanced understanding of antecedents of waste management practices of small hotels. Future studies should also examine the environmental attitudes of not only managers of small hotels but different categories of hotels including upscale hotels that have larger ecological footprints.

\subsection{Practical implications}

Results of this study show that though generally, environmental attitudes of managers predict waste management practices in hotels, the belief that humans are not exempted from

\section{Effects of managers' environmental attitudes}


IHR

35,1

the constraints of nature (anti-exceptionalism) is the most significant variable influencing pro-environmental behaviour, while the belief in humans causing detrimental harm to the physical environment (eco-crisis) is the least significant predictive variable concerning waste management in small hotels when socio-demographic characteristics serve as control variables. Thus, the ability of managers of small hotels and their willingness to initiate appropriate waste management practices depend on their environmental attitudes. Waste management problems can be addressed in small hotels by adopting softer sustainability strategies, such as environmental education geared towards creating environmental awareness and inculcating the right environmental values in hotel managers to change the way they view the environment. Also, because, in reality, small hotels lack the resources and capacity necessary for training management and staff, managers of small hotels should collaborate with hotel trade associations and regulatory agencies, such as the GTA, National Tourism Authorities, Destination Management Organisations, and Environmental Protection Agencies, to organise training programmes.

\subsection{Methodological limitations}

The current study highlights at least five limitations in the methodology. First, the use of quantitative research did not allow the researcher to gain greater insights into the environmental attitudes of managers and their influence on waste management practices in small hotels. As a result, future studies should adopt a qualitative approach to unearth the fine details of factors that influence the waste management practices of small hotels. Second, the study employed the WMH model which focuses on solid waste management. Thus, the management of gaseous and liquid wastes of the hotels was not adequately examined, which would be a worthwhile investigation in future research. Thirdly, the results of this study cannot be generalised due to the use of cross-sectional data. Future research should use longitudinal data to make causal inferences. Fourthly, given the limitations associated with the use of Harman's single factor test (Podsakoff et al., 2003), future research should consider the use of a rigorous statistical test such as common latent factor analysis. Finally, although $\mathrm{CMB}$ was not an issue in the current study, future studies should adopt more procedures to mitigate the effects of $\mathrm{CMB}$. For example, waste management practices and environmental attitudes should be measured at separate times.

\section{References}

Agyeiwaah, E. (2020), "The contribution of small accommodation enterprises to sustainable solid waste management", Journal of Hospitality and Tourism Management, Vol. 44, pp. 1-9.

Amérigo, M., Aragonés, J.I., de Frutos, B., Sevillano, V. and Cortés, B. (2007), "Underlying dimensions of ecocentric and anthropocentric environmental beliefs", The Spanish Journal of Psychology, Vol. 10 No. 1, pp. 97-103.

Anguera, N., Ayuso, S. and Fullana, P. (2000), "Implementation of EMS's in seasonal hotels", in Hillary, R. (Ed.), Assuring Sustainability: ISO 14000 Case Studies and Practical Experiences, Greenleaf Publishing, Sheffield, pp. 162-171.

Aragón-Correa, J.A., Matías-Reche, F. and Senise-Barrio, M.E. (2004), "Managerial discretion and corporate commitment to the natural environment", Journal of Business Research, Vol. 57, pp. 964-975.

Autry, C., Whipple, J., Cantor, D., Morrow, P., McElroy, J. and Montabon, F. (2013), "The role of individual and organisational factors in promoting firm environmental practices", International Journal of Physical Distribution and Logistics Management, Vol. 43 Nos 5/6, pp. 407-427.

Ball, S. and Taleb, M.A. (2011), "Benchmarking waste disposal in the Egyptian hotel industry", Tourism and Hospitality Research, Vol. 11 No. 1, pp. 1-18. 
Bilitewski, B., Hardtle, G. and Marek, K. (1994), "Waste management", in Weissbach, A. and Boeddicker, H. (Eds), Abfallwirtschaft, Eine Einfuhrung, Springer-Verlag, Berlin Heidelberg, p. 204.

Bohdanowicz, P. (2005), "European hoteliers' environmental attitudes - greening the business", Cornell Hotel and Restaurant Administration Quarterly, Vol. 46 No. 2, pp. 188-204.

Brügger, A., Kaiser, F.G. and Roczen, N. (2011), "One for all? Connectedness to nature, inclusion of nature, environmental identity, and implicit association with nature", European Psychologist, Vol. 16 No. 4, pp. 324-333.

Cassels, S. and Lewis, K. (2011), "SMEs and environmental responsibility: do actions reflect attitudes?", Corporate Social Responsibility and Environmental Management, Vol. 18 No. 3, pp. 186-199.

Chan, E.S.W. (2011), "Implementing environmental management systems in small-and medium-sized hotels', Obstacles", Journal of Hospitality and Tourism Research, Vol. 35 No. 1, pp. 3-23.

Cho, C.K., Cho, T.S. and Lee, J. (2019), "Managerial attributes, consumer proximity, and corporate environmental performance", Corporate Social Responsibility and Environmental Management, Vol. 26 No. 1, pp. 159-169.

Cordano, M. and Frieze, I.H. (2000), "Pollution reduction preferences of US environmental managers: applying Ajzen's theory of planned behaviour", Academy of Management Journal, Vol. 43, pp. 627-641.

Dalotă, M. and Grigore, S. (2010), "Successful implementation of knowledge management in small and medium enterprises", Managerial Challenges of the Contemporary Society, Vol. 6 No. 1, pp. 46-49.

Dibrell, C., Craig, J.B. and Hansen, E.N. (2011), "How managerial attitudes toward the natural environment affect market orientation and innovation", Journal of Business Research, Vol. 64 No. 4, pp. 401-407.

Dief, M.E. and Font, X. (2012), "Determinants of environmental management in the Red sea hotels: personal and organisational values and contextual variables", Journal of Hospitality and Tourism Research, Vol. 36 No. 1, pp. 115-137.

Dunlap, R.E., Liere, K.D., Van Mertig, A.G. and Jones, R.E. (2000), "Measuring endorsement of the new ecological paradigm: a revised NEP scale", Journal of Social Issues, Vol. 56 No. 3, pp. 425-442.

Erdogan, N. and Baris, E. (2007), "Environmental protection programs and conservation practices of hotels in Ankara, Turkey", Tourism Management, Vol. 28 No. 2, pp. 604-614.

Ferris, G.R., Frink, D.D., Galang, M.C., Zhou, J., Kacmar, K.M. and Howard, J.E. (1996), "Perceptions of organisational politics: predictions, stress-related implications, and outcomes", Human Relations, Vol. 49 No. 2, pp. 233-266.

Fishbein, M. and Ajzen, I. (1975), Belief, Attitude, Intention, and Behaviour: An Introduction to Theory and Research., Addison-Wesley, Reading, MA.

Ghana Tourism Authority (2016), Hotel Directory, Accra: Ghana Tourism Authority, Accra.

Hair, J., Black, W., Babin, B.J., Anderson, R.E. and Tatham, R.L. (2010), Multivariate Data Analysis, 7th ed., Prentice Hall, New Jersey, NJ, Upper Saddle River.

Hambrick, D.C. (2007), "Upper echelons theory: an update”, Academy of Management Review, Vol. 32, pp. 334-343.

Hawcroft, L.J. and Milfont, T.L. (2010), "The use (and abuse) of the new environmental paradigm scale over the last 30 years: a meta-analysis", Journal of Environmental Psychology, Vol. 30 No. 2, pp. 143-158.

Hiebl, M.R. (2014), "Upper echelons theory in management accounting and control research", Journal of Management Control, Vol. 24 No. 3, pp. 223-240.

Holden, A. (2008), Environment and Tourism, 2nd ed, Routledge, London.

Hoogendoorn, G., Grant, B. and Fitchett, J. (2015), “Towards green guest houses in South Africa: the case of Gauteng and KwaZulu-Natal", South African Geographical Journal, Vol. 97 No. 2, pp. 123-138.
Effects of managers' environmental attitudes 
IHR

35,1

Hu, L.T. and Bentler, P.M. (1999), "Cutoff criteria for fit indexes in covariance structure analysis: conventional criteria versus new alternatives", Structural Equation Modeling: A Multidisciplinary Journal, Vol. 6, pp. 1-55.

Jabbour, C.J.C., de Sousa Jabbour, A.B.L., Govindan, K., Teixeira, A.A. and de Souza Freitas, W.R. (2013), "Environmental management and operational performance in automotive companies in Brazil: the role of human resource management and lean manufacturing", Journal of Cleaner Production, Vol. 47, pp. 129-140.

Kasim, A. (2009), "Managerial attitudes towards environmental management among small and medium hotels in Kuala Lumpur", Journal of Sustainable Tourism, Vol. 17 No. 6, pp. 709-725.

Kim, S. and Yoon, J.H. (2010), "Environmental management of Korean hotels: a perspective of GMs", International Journal of Tourism Sciences, Vol. 10 No. 2, pp. 55-83.

Kollmuss, A. and Agyeman, J. (2002), "Mind the gap: why do people act environmentally and what are the barriers to pro-environmental behaviour?", Environmental Education Research, Vol. 8 No. 3, pp. 239-259.

Liao, Z. (2018), "Market orientation and firms' environmental innovation: the moderating role of environmental attitude", Business Strategy and the Environment, Vol. 27 No. 1, pp. 117-127.

López-Bonilla, L.M. and López-Bonilla, J.M. (2016), "From the new environmental paradigm to the brief ecological paradigm: a revised scale in golf tourism", Anatolia, Vol. 27, pp. 227-236.

Mateu-Sbert, J., Ricci-Cabello, I., Villalonga-Olives, E. and Cabeza-Irigoyen, E. (2013), "The impact of tourism on municipal solid waste generation: the case of Menorca Island (Spain)", Waste Management, Vol. 33 No. 12, pp. 2589-2593.

Mensah, I. (2006), "Environmental management practices among hotels in the greater Accra region", International Journal of Hospitality Management, Vol. 25 No. 3, pp. 414-431.

Mensah, I. (2019), Environmental Management Concepts and Practices for the Hospitality Industry, Cambridge Scholars Publishing, Newcastle Upon Tyne.

Mensah, I. (2020), "Waste management practices of small hotels in Accra: an application of the waste management hierarchy model”, Journal of Global Business Insights, Vol. 5 No. 1, pp. 33-46.

Milohnic, I. (2006), "Importance of public relations management in small hotels", Tourism and Hospitality Management, Vol. 12 No. 2, pp. 231-243.

Molina-Azorin, J.F., Claver-Cortes, E., Perira-Moliner, P. and Tari, J.J. (2009), "Environmental practices and firm's performance: an empirical analysis in the Spain hotel industry", Journal of Cleaner Production, Vol. 17, pp. 516-524.

Nordlund, A. and Garvill, J. (2002), "Value structures behind pro-environmental behaviour", Environment and Behaviour, Vol. 34 No. 6, pp. 740-756.

Park, J. and Kim, H.J. (2014), "Environmental proactivity of hotel operations: antecedents and the moderating effect of ownership type", International Journal of Hospitality Management, Vol. 37, pp. 1-10.

Park, J., Jeong Kim, H. and McCleary, K.W. (2014), "The impact of top management's environmental attitudes on hotel companies' environmental management", Journal of Hospitality and Tourism Research, Vol. 38 No. 1, pp. 95-115.

Phu Pham, S.T., Hoang, M.G. and Fujiwara, T. (2018), "Analysing solid waste management practices for the hotel industry", Global Journal of Environmental Science and Management, Vol. 4 No. 1, pp. 19-30.

Pirani, S.I. and Arafat, H.A. (2014), "Solid waste management in the hospitality industry: a review", Journal of Environmental Management, Vol. 146, pp. 320-336.

Podsakoff, P.M., MacKenzie, S.B., Lee, J.Y. and Podsakoff, N.P. (2003), "Common method biases in behavioural research: a critical review of the literature and recommended remedies", Journal of Applied Psychology, Vol. 88 No. 5, pp. 879-904.

Pryce, A. (2001), "Sustainability in the hotel industry", Travel and Tourism Analyst, No. 6, pp. 95-114. 
Radwan, H.R., Jones, E. and Minoli, D. (2012), "Solid waste management in small hotels: a comparison of green and non-green small hotels in Wales", Journal of Sustainable Tourism, Vol. 20 No. 4, pp. 533-550.

Scholz, P. and Voracek, J. (2016), "Organisational culture and green management: iinnovative way ahead in hotel industry”, Measuring Business Excellence, Vol. 20 No. 1, pp. 41-52.

Schultz, P.W. (2001), "The structure of environmental concern: concern for self, other people, and the biosphere”, Journal of Environmental Psychology, Vol. 21 No. 4, pp. 327-339.

Schultz, P.W., Shriver, C., Tabanico, J.J. and Khazian, A.M. (2004), "Implicit connections with nature", Journal of Environmental Psychology, Vol. 24, pp. 31-42.

Schwartz, S.H. (1977), "Normative influences on altruism", Advances in Experimental Social Psychology, Vol. 10 No. 1, pp. 221-279.

Stern, P.C. (2000), "Toward a coherent theory of environmentally significant behaviour", Journal of Social Issues, Vol. 56, pp. 407-424.

Tabachnick, B.G. and Fidell, L.S. (2007), Using Multivariate Statistics, 5th ed., Allyn \& Bacon/Pearson Education, Boston, MA.

Thompson, S.C. and Barton, M. (1994), "Ecocentric and anthropocentric attitudes toward the environment”, Journal of Environmental Psychology, Vol. 14 No. 1, pp. 149-157.

Tilley, F. (2000), “Small firms' environmental ethics: how deep do they go?”, in Hillary, R. (Ed.), Small and Medium-Sized Enterprises and the Environmental: Business Imperatives, Greenleaf Publishing, Sheffield, pp. 35-48.

Today Newspaper (2018), Accra Generates 3,000 Metric Tonnes of Waste in a Day, GN Media Group, Accra.

Tsai, Y.H., Wu, C.T. and Wang, T.M. (2014), "Attitude towards green hotel by hoteliers and travel agency managers in Taiwan”, Asia Pacific Journal of Tourism Research, Vol. 19 No. 9, pp. 1091-1109.

Tzschentke, N.A., Kirk, D. and Lynch, P.A. (2008), "Going green: decisional factors in small hospitality operations”, International Journal of Hospitality Management, Vol. 27 No. 1, pp. 126-133.

Vernon, J., Essex, S., Pinder, D. and Curry, K. (2003), “The 'greening' of tourism micro-businesses: outcomes of focus group investigations in South East Cornwall", Business Strategy and the Environment, Vol. 12 No. 1, pp. 49-69.

Waste Online (2006), After It's Been Binned, available at: http://www.wasteonline.org.uk/resources/ InformationSheets/WasteDisposal.htm\#top (accessed 21 May 2006).

Webster, K. (2000), Environmental Management in the Hospitality Industry: A Guide for Students and Managers, Cassell, London.

Williams, S. and Schaefer, A. (2013), "Small and medium-sized enterprises and sustainability: managers' values and engagement with environmental and climate change issues", Business Strategy and the Environment, Vol. 22 No. 3, pp. 173-186.

Zhang, P. and London, K. (2011), "Does globalisation benefit developed or developing country? - case studies on Chinese and Australian construction industry", International Conference on Advances in Education and Management, Springer, Heidelberg, Berlin, pp. 83-90.

Zorpas, A.A., Lasaridi, K., Voukkali, I., Loizia, P. and Inglezakis, V.J. (2012), "Solid waste from the hospitality industry in Cyprus", WIT Transactions on Ecology and the Environment, Vol. 166, pp. $41-49$.

Zorpas, A.A., Voukkali, I. and Loizia, P. (2015), "The impact of tourist sector in the waste management plans”, Desalination and Water Treatment, Vol. 56 No. 5, pp. 1141-1149.

Zutshi, A. and Sohal, A.S. (2004), "Adoption and maintenance of environmental management systems”, Management of Environment Quality, Vol. 15 No. 4, pp. 399-419.
Effects of managers' environmental attitudes 
IHR

35,1

126

\section{Further reading}

Allen, P. and Bennett, K. (2010), PASW Statistics by SPSS - A Practical Guide Version 18.0, 1st ed., Cengage Learning Australia Pty, Melbourne.

Wazng, R. (2012), "Investigations of important and effective effects of green practices in restaurants", Procedia-Social and Behavioural Sciences, Vol. 40, pp. 94-98.

\section{About the authors}

Ishmael Mensah PhD., CHE is a Associate Professor at the Department of Hospitality and Tourism Management, University of Cape Coast where he obtained his $\mathrm{PhD}$ in tourism. He is also a Certified Hospitality Educator. His research interests include environmental management in tourism and hospitality businesses, service quality and destination marketing. Ishmael Mensah is the corresponding author and can be contacted at: ikmensah@ucc.edu.gh

Dr Emmanuel Twumasi Ampofo is a lecturer at the Department of Human Resources and Organisational Development, Kwame Nkrumah University of Science and Technology. His research interests include human resource management and organisational behaviour, including human resource practices in hotels.

For instructions on how to order reprints of this article, please visit our website: www.emeraldgrouppublishing.com/licensing/reprints.htm Or contact us for further details: permissions@emeraldinsight.com 